\title{
Experimental findings of soil particle movement in 2D seepage failure of soil using Particle Image Velocimetry
}

\author{
T. Tanaka, S. Sannabe, S. Nagai, K. Kasamatsu \& K. Inoue \\ Graduate School of Agricultural Science, Kobe University, Nada Kobe 657-8501, Japan
}

\begin{abstract}
Seepage failure is one of the most important issues associated with the performance-based design of soil at high groundwater sites. We discuss the movement of soil particles with increase in the hydraulic head difference, $H$, in half $2 \mathrm{D}$ model tests on the seepage failure of soil in front of sheet piles using PIV analyses (Particle Image Velocimetry). The following conclusions were obtained: (1) At a certain value of $H_{\text {piv }}$ lower than $H_{y}$, the micro movement of soil particles is found around the bottom tip of a sheet pile wall, where $H_{\text {piv }}$ and $H_{y}$ are the hydraulic head differences at the start of soil particle movement using PIV analysis, and at the onset of deformation of the soil surface, respectively. (2) The location of the micro movement of soil particles corresponds reasonably well with the $\gamma_{\text {net }}<0$ region, where $\gamma_{\text {net }}$ is the net body force exerted on a unit volume of soil. (3) Micro movement of soil particles occurs at a hydraulic head difference of $73-100 \%$ of $H_{y}$. (4) PIV analyses show the boundaries between regions where soil particles do or do not move as well as the movement of sand particles. (5) The region of soil particle movement proves the validity of the prism of failure for Terzaghi's method and the prismatic failure concept.
\end{abstract}

\section{INTRODUCTION}

In the excavation of soil within a cofferdam with a high groundwater level, a hydraulic head difference between up- and downstream sides, $H$, causes seepage flow through the soil. Seepage failure, such as boiling or piping, is one of the crucial issues for soil. Downstream soil is subjected to an upward seepage flow, and in some cases soil particles can migrate and/or a bulk of soil can rise as a whole. The seepage failure occurs inside soil, and so when and where it in fact occurs, and what kind of events precede it have not been clarified. The H2D test apparatus was designed so as to observe the movement of soil particles, which is the half model of the 2D seepage failure test apparatus (or a previous model (Tanaka et al. 1999)). Twenty five seepage failure tests were conducted for various depths of soil, including noexcavation or excavation cases. In this paper, analyses were carried out on the behavior of soil particles using PIV (Particle Image Velocimetry), and the characteristics of seepage failure of soil are discussed.

\section{TEST APPARATUS AND SAND}

\subsection{Test apparatus}

A test apparatus for a half model test of twodimensional seepage failure of soil (H2D) is shown in Figure 1, which is the half model of the 2D seepage failure test apparatus (or a previous model
(Tanaka et al. 1999)). The test apparatus consists of three parts: seepage and water tanks, constant-head device, and open piezometers.

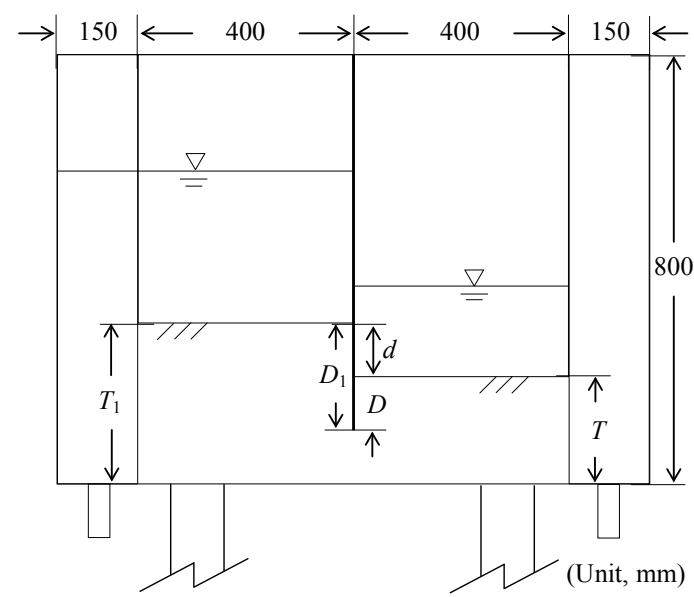

Figure 1. Schematic sketch showing a half model test apparatus.

The seepage tank is made of stainless steel, being $800 \mathrm{~mm}$ wide, $800 \mathrm{~mm}$ high, and $200 \mathrm{~mm}$ deep. The front of the tank is made of transparent acryl for observation of the behavior of soil particles inside, and the rear side of the tank is equipped with 322 piezometer holes for the measurement of pore water pressures. At the center of the seepage tank, a sheet pile of $3 \mathrm{~mm}$ thick is installed, and the clearance from the lower edge of the sheet pile to the bottom of the 
tank is $100 \mathrm{~mm}$. Water tanks of $150 \mathrm{~mm}$ wide, 800 $\mathrm{mm}$ high, and $200 \mathrm{~mm}$ deep are fitted on the left and right-hand sides of the seepage tank (shown in Fig.1).

The upstream water head is raised stepwise and maintained constantly using the constant-head device. Seepage water flows through the sand model under the difference in the hydraulic head, $H$, between the downstream water level at the top of the partition wall in the downstream water tank and the upstream water level kept constant by the constant-head device.

The 16 manometer plates with 20 pipes of 1,500 $\mathrm{mm}$ long and $8 \mathrm{~mm}$ in the inside diameter (320 open piezometers in total) are used for measurements of pore water pressures. The water pressures can be read from 320 open piezometers connected to the piezometer holes in the rear side of the seepage tank.

\subsection{Test sand}

Lake Biwa Sand 3 is used as a test sand. The physical properties and grain size distribution curve are illustrated in Table 1 and Figure 2, where the coefficient of uniformity, $U_{c}$, is defined as the ratio of $60 \%$ to $10 \%$ size of sand particles, $D_{60} / D_{10}$. The closer the value is to 1 , the more uniform the sand is. Table 1 and Figure 2 show that the test sand is classified as uniform and fine sand.

\section{PROCEDURE FOR MAKING AND SETTING UP SAND MODELS}

The procedure for making and setting up sand models is as follows:

(1) Test sand is weighed with several containers.

(2) The containers are filled with water, and sand is soaked for about one week until it is fully saturated with water due to deaeration through being stirred several times.

(3) The seepage tank is filled with water, and connected to the water-pressure measurement system so that the water can flow freely through vinyl tubes from the piezometer holes in the rear side of the seepage tank to the open piezometers on the manometer plates.

(4) The test sand saturated with water is poured by hand, little by little, at the same time from the left and right-hand sides. The sand is placed in about 20 layers and compacted with an aluminum rod of 5 $\mathrm{mm}$ in diameter, $580 \mathrm{~mm}$ in length, and $32 \mathrm{~g}$ in weight. For each layer, the compacting rod is dropped from a $100 \mathrm{~mm}$-height 12 times. The test sand is compacted to the relative density $D_{r} \approx 50 \%$.

(5) The water tanks are mounted on the left and right-hand sides of the seepage tank.

(6) The datum line is set up using the first-class level PL1.

(7) The sand model is held in this state for one night to promote a stable condition.

(8) The seepage failure experiment is started on the next day.
Table 1. Physical properties of test sand.

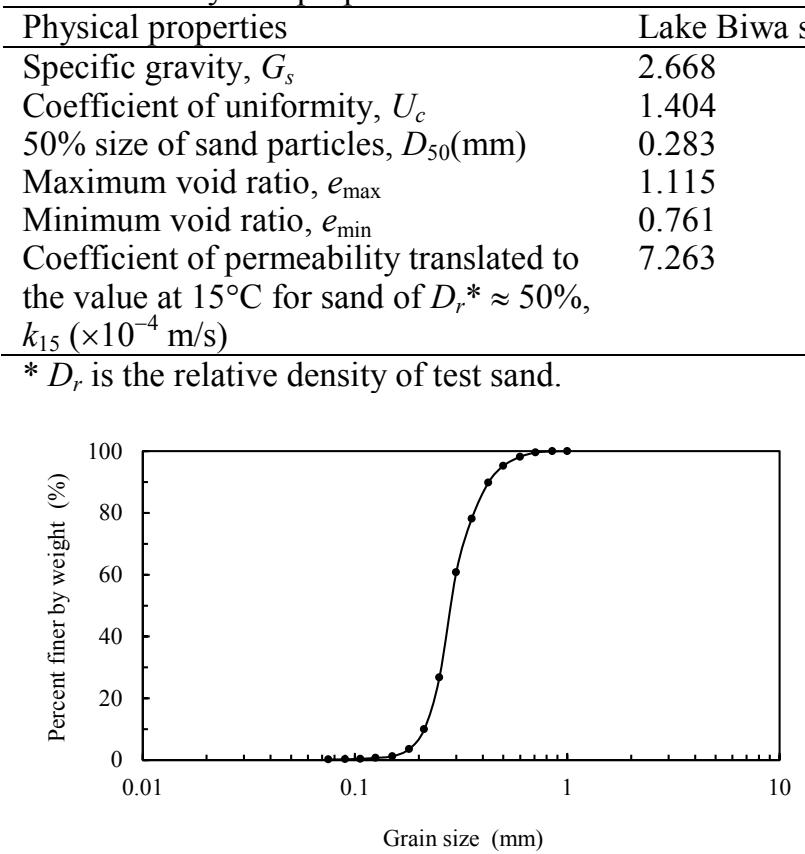

Figure 2. Grain size distribution of test sand.

\section{SEEPAGE FAILURE TESTS}

An upstream water head is raised stepwisely until the sand model changes in shape and collapses. The increase in hydraulic head difference, $\Delta H$, is about $20 \%$ of the critical hydraulic head difference of the sand model, $H_{c}$, in early steps $\left(H<0.8 H_{c}\right)$, where $H_{c}$ is the theoretical critical hydraulic head difference calculated using pfc-2D (Tanaka 1996, Tanaka \& Verruijt 1999). $\Delta H$ is then gradually reduced by half, by half again, and so on, and finally around $2 \%$ of $H_{c}$ in the vicinity of $H=H_{c}$. At each step of $H$, the following data items are measured, after verifying that the seepage flow is in a steady state:

(1) Quantity of water flowing through soil is measured a few times and averaged.

(2) Temperatures of water on up- and downstream sides of the seepage tank are measured and averaged.

(3) The quantity of discharge is translated to the value at 15 degrees Centigrade, $Q_{15}$.

(4) Pore water pressures are measured at all points of piezometer holes in sand and water, being referred to as "Detailed measurements", and at certain selected points, as "Simplified measurements". Using the measured pore water pressures, the difference between hydraulic heads on the up- and downstream sides, $H$, is calculated, and an $H-Q_{15}$ curve is plotted. The equi-potential lines generated by the experiment are drawn from detailed measurements.

(5) The heights of the soil surface are measured at several chosen points along the measurement line. The measurement line is the center line of the test apparatus (or the center in the depth direction perpendicular to the page). The changes in surface configurations of test soil are discussed. 
Table 2. Series of tests

\begin{tabular}{|c|c|c|c|c|c|c|c|}
\hline Test No. & $e(\mathrm{~m})$ & $T_{1}(\mathrm{~m})$ & $D_{1}(\mathrm{~m})$ & $T(\mathrm{~m})$ & $D(\mathrm{~m})$ & $d(\mathrm{~m})$ & Excavation \\
\hline E0401 & 0.93882 & 0.14989 & 0.05025 & 0.14989 & 0.05025 & 0.00000 & No \\
\hline E0402 & 0.93554 & 0.19960 & 0.09997 & 0.19960 & 0.09997 & 0.00000 & No \\
\hline E0403 & 0.94298 & 0.22540 & 0.12572 & 0.22540 & 0.12572 & 0.00000 & No \\
\hline E0404 & 0.94074 & 0.22578 & 0.12614 & 0.19955 & 0.09992 & 0.02623 & Yes \\
\hline E0405 & 0.93900 & 0.22448 & 0.12484 & 0.17525 & 0.07562 & 0.04923 & Yes \\
\hline E0406 & 0.93641 & 0.22483 & 0.12519 & 0.14940 & 0.04977 & 0.07543 & Yes \\
\hline E0407 & 0.93964 & 0.19998 & 0.10034 & 0.17508 & 0.07544 & 0.02490 & Yes \\
\hline E0408 & 0.93433 & 0.24945 & 0.14982 & 0.24945 & 0.14982 & 0.00000 & No \\
\hline E0409 & - & - & - & - & - & - & - \\
\hline E0410 & - & - & - & - & - & - & - \\
\hline E0411 & 0.93734 & 0.27465 & 0.17502 & 0.27465 & 0.17502 & 0.00000 & No \\
\hline E0412 & 0.93667 & 0.22500 & 0.12527 & 0.19950 & 0.09977 & 0.02550 & Yes \\
\hline E0413 & 0.92504 & 0.14891 & 0.04928 & 0.14891 & 0.04928 & 0.00000 & No \\
\hline E0414 & 0.94256 & 0.20033 & 0.10069 & 0.20033 & 0.10069 & 0.00000 & No \\
\hline E0415 & - & - & - & - & - & - & - \\
\hline E0416 & - & - & - & - & - & - & - \\
\hline E0417 & 0.94566 & 0.20065 & 0.10102 & 0.15048 & 0.05084 & 0.05018 & Yes \\
\hline E0418 & 0.93515 & 0.19990 & 0.10027 & 0.17415 & 0.07452 & 0.02575 & Yes \\
\hline E0419 & 0.93875 & 0.17490 & 0.07527 & 0.17490 & 0.07527 & 0.00000 & No \\
\hline E0420 & 0.93648 & 0.22490 & 0.12527 & 0.19945 & 0.09982 & 0.02545 & Yes \\
\hline E0421 & 0.94002 & 0.22515 & 0.12552 & 0.14990 & 0.05027 & 0.07525 & Yes \\
\hline E0422 & 0.93914 & 0.20008 & 0.10044 & 0.14978 & 0.05014 & 0.05030 & Yes \\
\hline E0423 & 0.93849 & 0.17488 & 0.07524 & 0.17488 & 0.07524 & 0.00000 & No \\
\hline E0424 & 0.93212 & 0.20020 & 0.10057 & 0.14840 & 0.04877 & 0.05180 & Yes \\
\hline E0425 & 0.93961 & 0.19990 & 0.10027 & 0.19990 & 0.10027 & 0.00000 & No \\
\hline
\end{tabular}

* Test Nos. E0409, E0410, E0415, and E0416 are cases of other test series.

(6) Photos are taken by a digital camera from the front of the test apparatus. The digital photos are processed using PIV analyses.

PIV (Particle Image Velocimetry) is one of the image-analyzing methods for measuring the movement of a pattern image of particles. For the image visualized by the pattern of sand particle distribution in the flow region, two bitmap images (continuously taken) are compared, and the displacement of the (recurrent) pattern image of particles is calculated. The displacement obtained represents a velocity for the photographing interval of two digital photos. In our experiments, the calculated "velocity" indicates what is called the "displacement" of a sand particle between the two test stages. In the PIV analyses, the pattern tracking algorithm is used in which the similarity of grey level patterns is defined with the accumulation of grey level differences between corresponding pixels (Kaga et al. 1994, Kimura et al. 1992). The accumulations are executed in parts and the candidates which differ significantly from the most promising candidate are abandoned successively through F-inspection. In the PIV analyses, the behavior of soil particles can be obtained without coloring matter or an observational point target. So, the actual movement of soil particles themselves can be clarified. The program soft "Flow PIV" by Library Co., Ltd. (2007 Edition) was used in this study.

The series of tests for sand models is numbered from E0401 to E0425, as shown in Table 2. Notation is as follows referring to Figure 1: $e$ is the void ratio of soil, $T_{1}$ and $D_{1}$ are the total depth of soil and penetration depth of sheet piles on the upstream side, respectively, $T$ and $D$ are those on the downstream side, and $d\left(=D_{1}-D\right)$ is the excavation depth for the excavation model.

\section{SEEPAGE FAILURE PHENOMENON OF SOIL}

Here, we consider the experimental results of the test E0414, which is for the no-excavation case, and has the dimensions: $T_{1}=T=20.03 \mathrm{~cm}, D_{1}=D=10.07$ $\mathrm{cm}, d=0.00 \mathrm{~cm}$, and $D_{r}=48.71 \%$.

\section{$5.1 H-Q_{15}$ curve and critical hydraulic head differences $\left(H_{d}\right.$ and $\left.H_{f}\right)$}

Figure 3 shows the $H-Q_{15}$ curve for the test E0414. It can be observed from Figure 3 that $Q_{15}$ increases linearly with increasing $H$ until a certain value, $H_{d}$. The $H_{d}$ value is referred to as the hydraulic head difference at which the $H-Q_{15}$ curve diverts from linearity. The linear relationship does not hold and discharge by the experiment increases abruptly when $H$ goes beyond $H_{d}$. As $H$ increases beyond $H_{d}, Q_{15}$ becomes larger, and more steeply than before with increasing $H$. This is because, just at this point, the soil loosens on the downstream side, the void space enlarges, permeability of the soil grows larger, and discharge increases non-linearly with $H$. As stated below, at almost the same point of $H_{y}$ as $H_{d}$, the soil surface begins to settle on the upstream side and rise on the downstream side. When $H$ increases even further, the ground finally collapses at the hydraulic head difference at failure, $H_{f}$. 


\subsection{Hydraulic head difference at the onset of deformation, $H_{y}$}

Figure 4 shows the hydraulic head difference, $H$, and the heights of soil at points adjacent to the sheet pile wall, $Y$. It can be seen from the $H-Y$ curve that the height of the soil surface is constant with increasing $H$ until a certain value, $H_{y}$. When $H$ increases beyond $H_{y}$, the soil surface begins to settle on the upstream side and rise on the downstream side. $H_{y}$ values are obtained on the up- and downstream sides as $H_{y u}$ and $H_{y d}$, respectively. The smaller value of these two is taken as $H_{y}$, which is referred to as the hydraulic head difference at the onset of deformation. The experimental results lead to the interesting conclusion of $H_{y}=H_{d}$ (Sannabe et al. 2014). So, it is thought that the abrupt change of $Q$ and deformation (upstream settlement and downstream rise) of soil occur in conjunction with each other. The ground is subjected to irreversible damage and cannot be restored when $H$ increases beyond $H_{y}$. So, the head difference, $H$, must be designed not to be above $H_{y}$.

\subsection{FEM mesh and equi-potentials by experiment}

Figure 5 shows the FEM mesh for the test E0414, in which nodal points in soil coincide with locations of piezometer holes (190 in this case). The equipotentials in the experiment for the test E0414 are shown in Figure 6, in which the increment of equipotentials are one sixth of the head difference. Equipotential lines are horizontally symmetrical, so it is thought that the test soil is created homogeneously.

\section{PIV ANALYSES}

Now, let us consider the results of the PIV analyses on seepage failure of soils in the cases of noexcavation and excavation.

\subsection{In the case of no-excavation}

Here, we consider the test E0414 in the case of noexcavation. PIV analyses prove that, with increasing $H$, the micro movement of soil particles is not observed at first, but found at the smaller value of $H=$ $22.161 \mathrm{~cm}$ than $H_{y}\left(=H_{d}\right)$ around the bottom tip of sheet piles, as shown in Figure 7. The displacements of soil particles are about $0.011-0.017 \mathrm{~cm}$. The upstream settlement and downstream rise of the soil surface were not observed at this point. Since the downstream region of the micro movement of soil particles near the bottom tip of the sheet pile wall corresponds reasonably well with the region of $\gamma_{\text {net }}<$ 0, as shown in Figure 8 (Kochina 1962, Matsuo et al. 1971), this phenomenon is thought to be associated with the occurrence of the $\gamma_{\text {net }}<0$ region. The value of $\gamma_{\text {net }}\left(=\gamma^{\prime}-i_{z} \gamma_{w}\right)$ is the net body force exerted on a unit volume of soil. The vertical component of the hydraulic gradient, $i_{z}$, is taken as positive if it is directed upward.

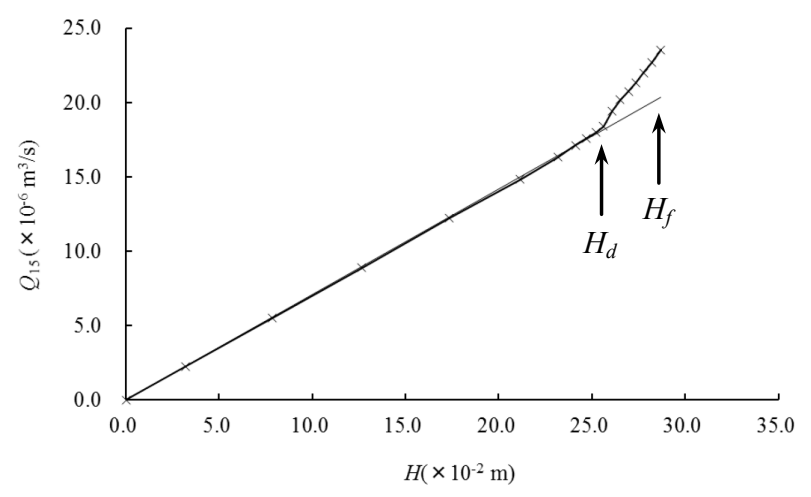

Figure 3. $H-Q_{15}$ curve (E0414).

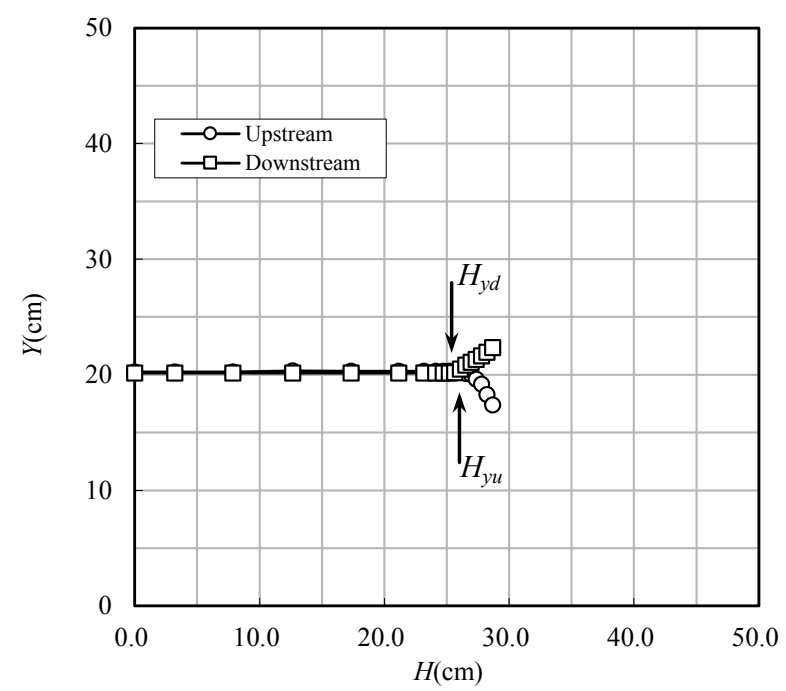

Figure 4. $H-Y$ curve (E0414).

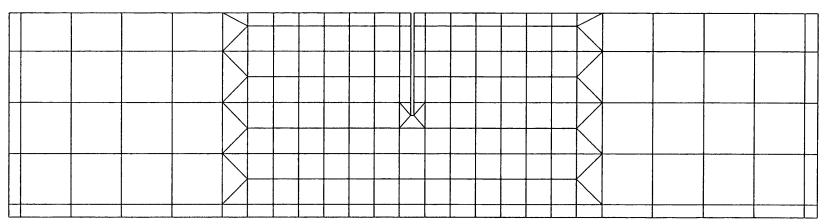

Figure 5. FEM mesh for the test E0414.

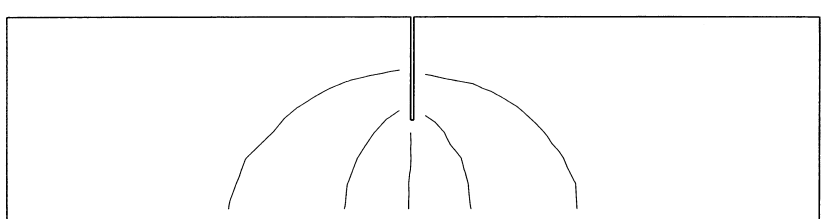

Figure 6. Equi-potential lines obtained by the test E0414.

Table 3. $\quad H_{\text {piv }}, H_{v}$ and $H_{\text {piv }} / H_{v}$ (No-excavation).

\begin{tabular}{llll}
\hline Test No. & $H_{\text {piv }}(\mathrm{cm})$ & $H_{\nu}(\mathrm{cm})$ & $H_{\text {piv }} / H_{v}(\%)$ \\
\hline E0401 & 9.287 & 12.687 & 73.200 \\
E0402 & 20.955 & 25.642 & 81.720 \\
E0403 & 30.632 & 32.450 & 94.400 \\
E0408 & 38.420 & 41.353 & 92.910 \\
E0411 & 44.026 & 47.352 & 92.980 \\
E0413 & 9.775 & 10.596 & 92.260 \\
E0414 & 22.161 & 25.643 & 86.420 \\
E0419 & 18.174 & 18.860 & 96.360 \\
E0423 & 19.281 & 19.289 & 99.960 \\
E0425 & 24.767 & 26.382 & 93.880
\end{tabular}




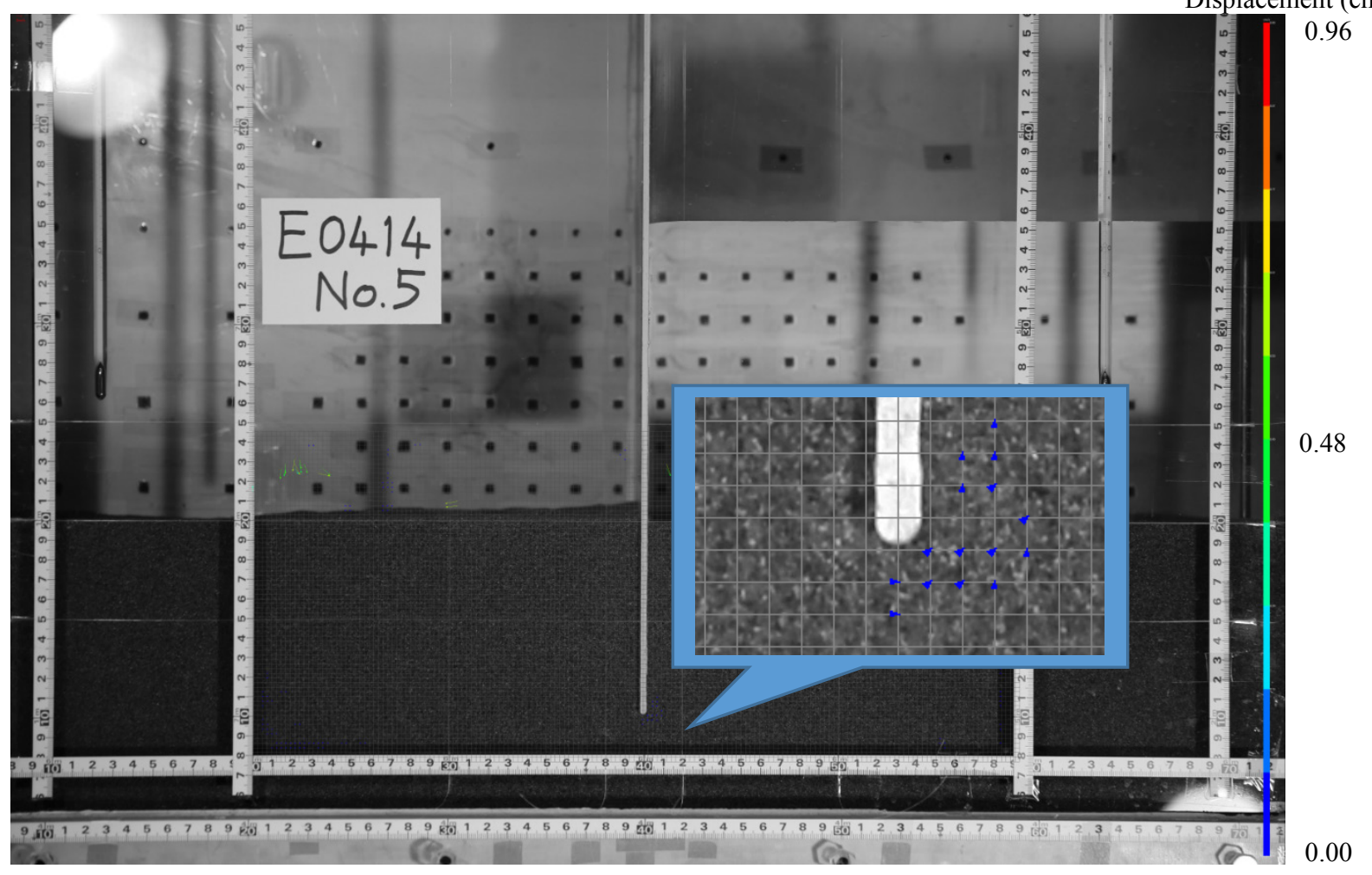

Figure 7. Micro movement of soil particles around the bottom tip of sheet piles (E0414) $(H=21.155 \rightarrow 23.167 \mathrm{~cm})$.

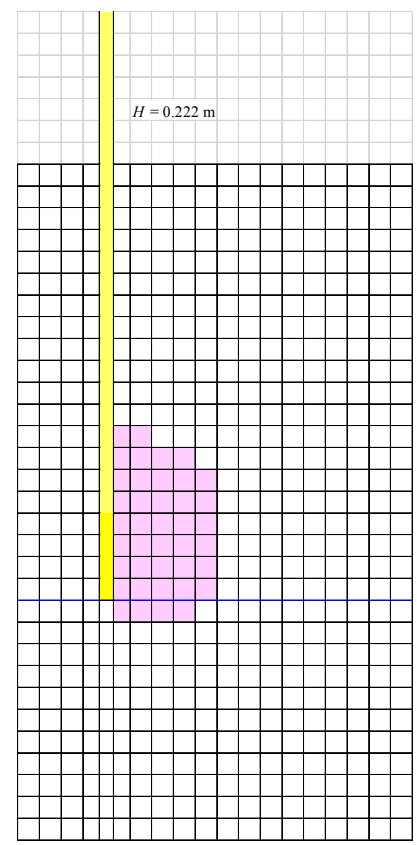

Figure 8. Region of $\gamma_{\text {net }}<0(\mathrm{E} 0414, H=22.200 \mathrm{~cm})$.

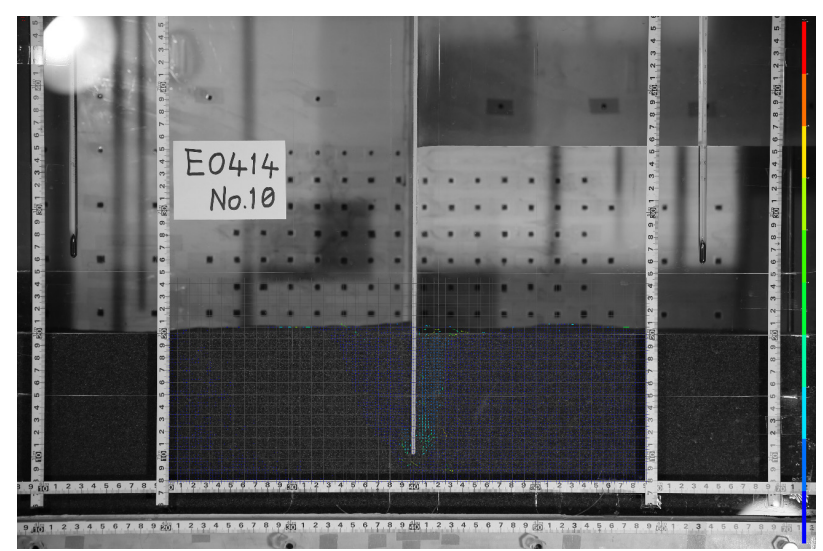
(a) At the value just beyond $H_{y}(H=25.616 \rightarrow 26.076 \mathrm{~cm})$.
Figure 9. PIV images with increasing $H$ at different stages $H$ beyond $H_{v}(\mathrm{E} 0414)$

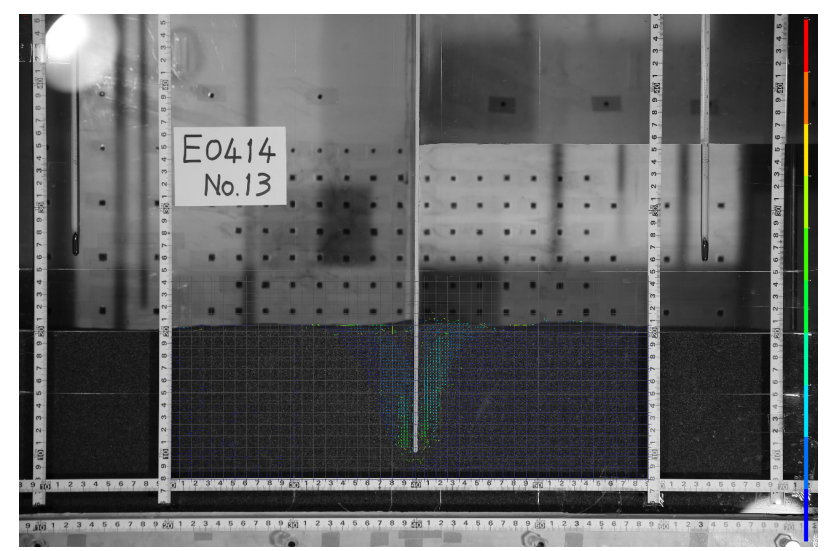

(b) At the value larger than $H_{y}(H=26.961 \rightarrow 27.344 \mathrm{~cm})$.

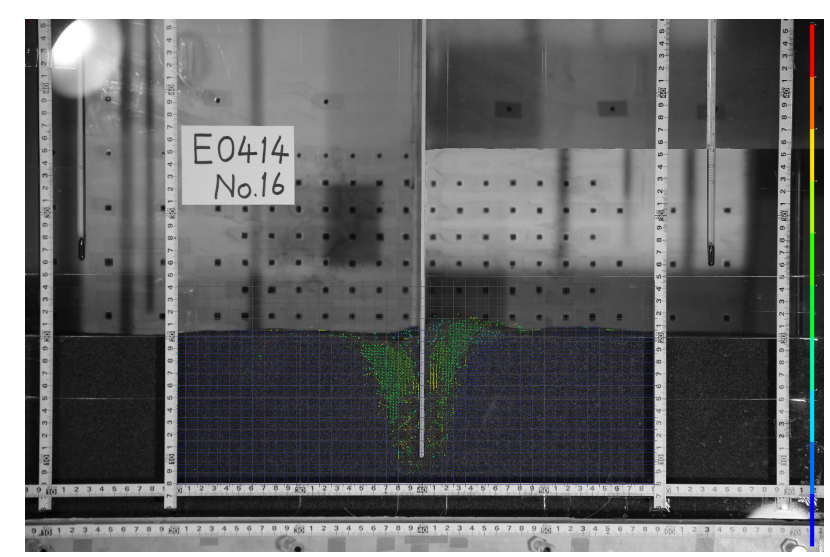

(c) At 1 step earlier than failure $(H=28.217 \rightarrow 28.686 \mathrm{~cm})$. 
Here, we consider the behavior of soil particles near the bottom tip of sheet piles. Although sand particles can migrate individually at an early stage of $H$, some soil particles move simultaneously (as a lump) at the point of $H=H_{\text {piv. }}$. For the test E0414 $\left(H_{d}=25.820 \mathrm{~cm}, H_{y}=25.643\right.$, and $\left.H_{f}=28.920 \mathrm{~cm}\right)$, $H_{\text {piv }}$ is $22.161 \mathrm{~cm}$ which equals $0.86 H_{y}$. Thus, the micro movement of soil particles around the bottom tip of the sheet pile wall occurs a little bit earlier than the downstream rising of the soil surface. Writing the equation as $H_{\text {piv }}=\alpha H_{y}$ with the use of $\alpha$, the $\alpha$ values are given as $0.73-1.00$ for the tests of the no-excavation cases, as shown in Table 3 . It is thus found that, for the fine and medium-density sand, sand particles move near the bottom tip of sheet piles at the lower hydraulic head difference of $H_{\text {piv }}$ than $H_{y}$. When the penetration depth of a sheet pile is shallow, local failure of piping occurs, and the $H_{\text {piv }}$ value becomes close to $H_{y}$.

To avoid the micro movement of soil particles around the bottom tip of the sheet pile wall, the hydraulic head difference of $H$ is not to exceed $H_{\text {piv }}$ during construction work. Compacting the downstream soil around the bottom tip of sheet piles and/or making it impervious through techniques such a grout injection is one of the best ways to improve the stability against seepage failure of the soil.

Next, we consider the analytical results obtained by PIV analyses with increase in $H$ beyond $H_{y}$. Figure 9 shows the PIV images with increasing $H$ at different stages: (a) at the value just beyond $H_{y}(H=$ $25.616 \rightarrow 26.076 \mathrm{~cm}),(\mathrm{b})$ at the value larger than $H_{y}$ $(H=26.961 \rightarrow 27.344 \mathrm{~cm})$, and $(\mathrm{c})$ at 1 step earlier than failure $(H=28.217 \rightarrow 28.686 \mathrm{~cm})$.

When $H$ has just exceeded $H_{y}$, as shown in Figure 9 (a), the downstream soil rises to about $2.4 \mathrm{~cm}$ wide adjacent to the sheet pile wall. The width of $2.4 \mathrm{~cm}$ is a little bit narrower than the width of Terzaghi's prism of failure $D / 2=5.0 \mathrm{~cm}$ in this test case. The displacement of sand particles is upward and $0.10-$ $0.12 \mathrm{~cm}$ in magnitude at the surface of soil. The soil particle movement is prominent on the downstream side and about $2.4 \mathrm{~cm}$ in width at the point $5 \mathrm{~cm}$ above the bottom tip of sheet piles. The displacement of sand particles is about $0.10-0.16 \mathrm{~cm}$ (on the downstream side) at that point.

When $H$ is increasing beyond $H_{y}$, the deformation of the soil surface (upstream settlement and downstream rise) is proceeding. With an increase in the deformation of soil, as shown in Figure 9 (b), the region of sand particle movement becomes larger on the upstream side than on the downstream side, and the width of soil movement is about $2.9 \mathrm{~cm}$ (upstream) and $2.4 \mathrm{~cm}$ (downstream) at the point $5 \mathrm{~cm}$ above the bottom tip of sheet piles. The displacement of sand particles is about $0.10-0.26 \mathrm{~cm}$ at that point.
When the soil approaches failure, as shown in Figure 9 (c), the range of soil particle movement is about $3.2 \mathrm{~cm}$ at the point $5 \mathrm{~cm}$ above the bottom tip of sheet piles. The displacement of sand particles is about $0.10-0.65 \mathrm{~cm}$ at that point.

It can be found from Figures 9 (a), (b), and (c) that the PIV analyses show the boundaries between regions where soil particles do or do not move as well as the movement of sand particles. On the downstream side, the region of soil particle movement is less than $D / 2$ at the start of soil deformation, and increases with the progression of soil deformation. The width of soil particle movement also becomes wider as it moves upward. The movement of soil particles is limited to the region of approximately the depth, $D$, and width, $D / 2$, which proves the validity of Terzaghi's method and the prismatic failure concept, where $D$ is the penetration depth of sheet piles.

\subsection{In the case of excavation}

Consider the test E0418 in the case of excavation, which has the dimensions: $T_{1}=20.000 \mathrm{~cm}, D_{1}=$ $10.027 \mathrm{~cm}, T=17.425 \mathrm{~cm}, D=7.452 \mathrm{~cm}, d=2.575$ $\mathrm{cm}$, and $D_{r}=50.795 \%$. The same things can be said for analytical results of PIV in the excavation case as in the no-excavation case, as follows:

At a certain value of $H_{\text {piv }}$ lower than $H_{y}$, the micro movement of soil particles is found around the bottom tip of a sheet pile wall, as shown in Figure 10. For the test E0418 $\left(H_{d}=20.093 \mathrm{~cm}, H_{y}=20.004\right.$, and $\left.H_{f}=24.910 \mathrm{~cm}\right), H_{\text {piv }}$ is given as $18.559 \mathrm{~cm}$ which equals $0.93 H_{y}$ (or $\alpha=0.93$ ). The location of micro movement of soil particles corresponds reasonably well with the $\gamma_{\text {net }}<0$ region, as shown in Figure 11 . The $\alpha$ values are given as $0.74-0.99$ for the tests of the excavation cases, as shown in Table 4. When the downstream penetration depth of a sheet pile is shallow, local failure of piping occurs, and the $H_{\text {piv }}$ value becomes close to $H_{y}$.

\begin{tabular}{lcll} 
Table 4. & $H_{\text {piv }}, H_{y}$ and $H_{\text {piv }} / H_{y}$ (Excavation). \\
\hline Test No. & $H_{\text {piv }}(\mathrm{cm})$ & $H_{y}(\mathrm{~cm})$ & $H_{\text {piv }} / H_{y}(\%)$ \\
\hline E0404 & 24.534 & 27.279 & 89.936 \\
E0405 & 16.977 & 23.034 & 73.703 \\
E0406 & 14.032 & 14.693 & 95.496 \\
E0407 & 18.267 & 20.320 & 89.897 \\
E0412 & 24.318 & 26.081 & 93.238 \\
E0417 & 14.618 & 14.809 & 98.710 \\
E0418 & 18.559 & 20.004 & 92.774 \\
E0420 & 26.437 & 26.549 & 99.578 \\
E0421* & - & 14.123 & - \\
E0422 & 13.091 & 13.353 & 98.038 \\
E0424* & 13.200 & - & - \\
\hline$* H_{\text {piv }}\left(\right.$ E0421) and $H_{y}(\mathrm{E} 0424)$ could not be obtained.
\end{tabular}




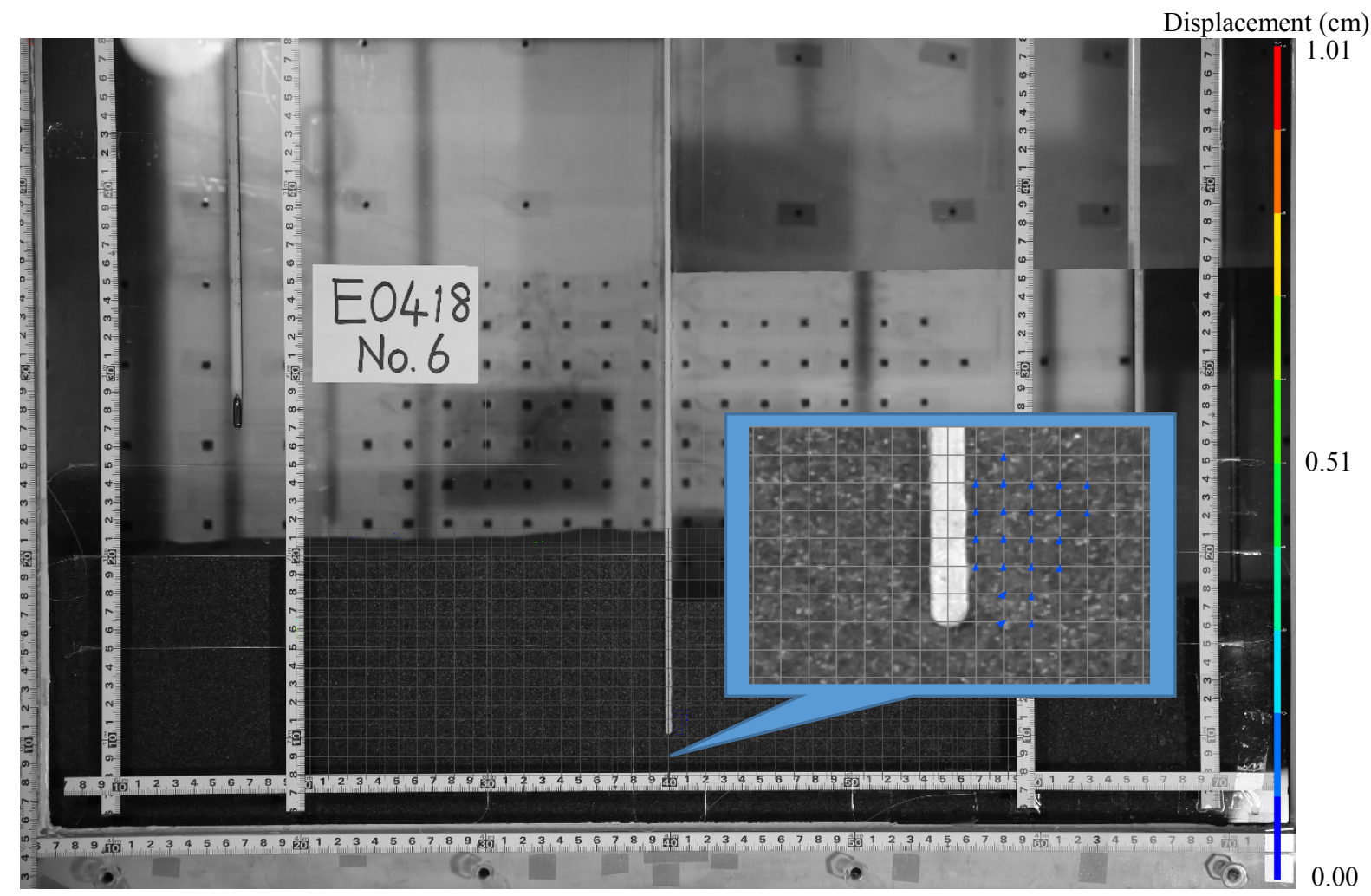

Figure 10. Micro movement of soil particles around the bottom tip of sheet piles (E0418) $(H=18.251 \rightarrow 18.866 \mathrm{~cm})$.

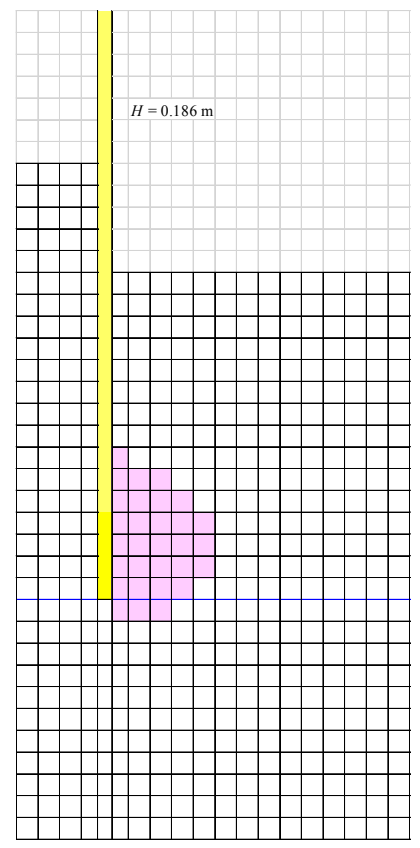

Figure 11. Region of $\gamma_{\text {net }}<0(\mathrm{E} 0418, H=18.600 \mathrm{~cm})$.

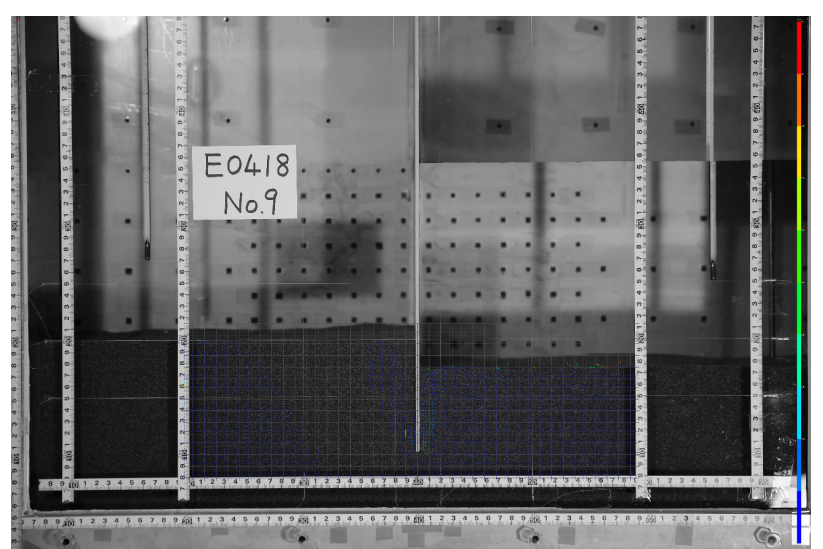

(a) At the value just beyond $H_{y}(H=19.923 \rightarrow 20.291 \mathrm{~cm})$.

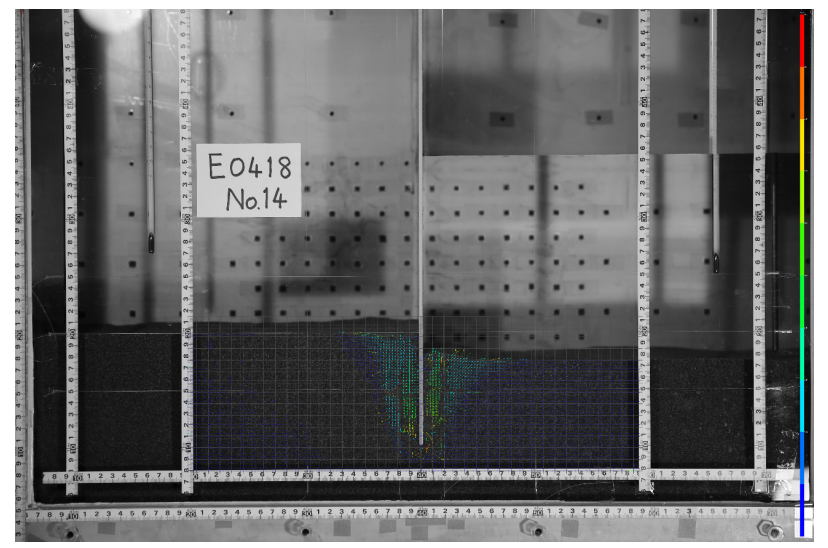

(b) At the value larger than $H_{y}(H=22.216 \rightarrow 22.961 \mathrm{~cm})$.

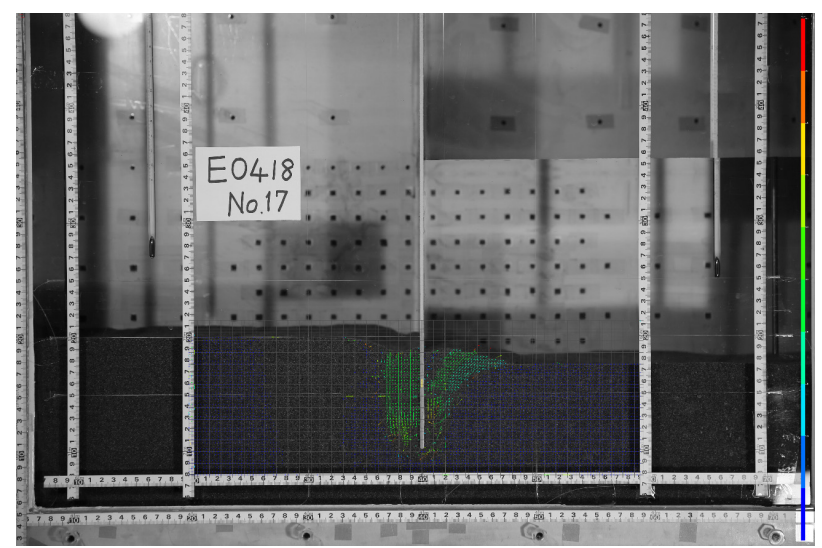

(c) At 2 step earlier than failure $(H=23.848 \rightarrow 24.269 \mathrm{~cm})$ Figure 12. PIV images with increasing $H$ at different stages $H$ beyond $H_{y}$ (E0418). 
Consider the analytical results obtained by PIV analyses with an increase in $H$ beyond $H_{y}$. Figure 12 shows the PIV images with increasing $H$ at different stages: (a) at the value just beyond $H_{y}(H=19.923$ $\rightarrow 20.291 \mathrm{~cm}),(\mathrm{b})$ at the value larger than $H_{y}(H=$ $22.216 \rightarrow 22.961 \mathrm{~cm})$, and (c) at 2 step earlier than failure $(H=23.848 \rightarrow 24.269 \mathrm{~cm})$. It can be seen from Figures 12 (a), (b), and (c) that the PIV analyses show the boundaries between regions where soil particles do or do not move as well as the movement of sand particles.

\section{CONCLUSIONS}

Seepage failure is one of the most important issues associated with the performance-based design of soil at high groundwater sites. Here, we discussed the movement of soil particles with an increase in the hydraulic head difference, $H$, in the half model tests on seepage failure of 2D soil in front of sheet piles (or H2D model tests), using analytical results of PIV (Particle Image Velocimetry). The following conclusions were obtained:

(1) When $H$ increases beyond $H_{d}\left(\approx H_{y}\right)$, an upstream settlement and downstream rise of the soil surface occur. PIV analyses show that soil particles move upward near a sheet pile wall, and the region of soil particle movement spreads upwards far from the wall. $H_{d}$ and $H_{y}$ are hydraulic head differences at an abrupt change in the $H-Q_{15}$ curve and at the onset of deformation of soil surface, respectively.

(2) At a certain value of $H_{\text {piv }}$ lower than $H_{y}$, the micro movement of soil particles is found around the bottom tip of a sheet pile wall, where $H_{\text {piv }}$ is the hydraulic head difference at the start of soil particle movement using PIV analysis.

(3) The location of micro movement of soil particles corresponds reasonably well with the $\gamma_{\text {net }}<0$ region. The value of $\gamma_{\text {net }}\left(=\gamma^{\prime}-i_{z} \gamma_{w}\right)$ is the net body force exerted on a unit volume of soil, where $\gamma^{\prime}$ and $\gamma_{w}$ are the buoyant unit weight of soil and unit weight of water. The vertical component of the hydraulic gradient, $i_{z}$, is taken as positive if it is directed upward.

(4) Micro movement of soil particles occurs at a hydraulic head difference of $73-100 \%$ of $H_{y}$ for the no-excavation, and $74-99 \%$ for the excavation case.

(5) When the penetration depth of a sheet pile is shallow, local failure of piping occurs and the $H_{\text {piv }}$ value becomes close to $H_{y}$.

(6) PIV analyses show the boundaries between regions where soil particles do or do not move as well as the movement of sand particles.

(7) On the downstream side, the movement of soil particles is limited to the region of approximately the depth, $D$, and width, $D / 2$, which proves the validity of Terzaghi's method and the prismatic failure concept, where $D$ is the penetration depth of sheet piles.
(8) To prevent micro movement of soil particles around the bottom tip of a sheet pile wall, the hydraulic head difference must not exceed the value of $H_{\text {piv }}$, which is usually a lower value than $H_{y}$.

(9) It is thought that grout injection around the bottom tip of sheet piles is effective for increasing stability to resist the seepage failure of soil.

\section{ACKNOWLEDGEMENT}

A part of this work was supported by JSPS KAKENHI Grant Number 24380131. We wish to express our deepest thanks to JSPS.

\section{REFERENCES}

Kaga, A, Inoue, Y. and Yamaguchi, K. 1994. Pattern tracking algorism for airflow measurement through digital image processing of visualized images. Journal of the Visualization Society of Japan, 14 (53): 108-115 (In Japanese). (April 1994)

Kimura, I., Yamashita, N. and Kuroe, Y. 1992. Determination of erroneous velocity vectors using neutral network. Proceedings of the Annual Meeting on the Fluids Engineering Division, JSME (The Japan Society of Mechanical Engineers): 310-312 (In Japanese). (1992.08.27-28)

Library Co. Ltd. ed. 2007. User's Manual "Flow PIV", 48pages, 2007 Edition (In Japanese).

Matsuo, S., Kohno, I. and Kubota, H. 1971. Discussion on seepage flow through soil under sheet piles and stability of the soil. Proceedings of the 6th Annual Meeting of Japanese Society of Soil Mechanics and Foundation Engineering: 487-490 (In Japanese).

Polubarinova-Kochina, P.Ya. 1962. Theory of Groundwater Movement, Translated from the Russian by J.M.R. de Wiest, Princeton: Princeton University Press: 85-88.

Sannabe, S., Tanaka, T., Tachimura, R. and Inoue, K. 2014. Seepage failure experiments on sand in a 2D half model The mechanism and practical approach to analyze-. Proceedings of the 2014 Annual Meeting of JSIDRE (The Japanese Society of Irrigation, Drainage and Rural Engineering): 794-795 (In Japanese).

Tanaka, T. 1996. Seepage failure of sand within a cofferdam Prismatic failure concept and analytical consideration-. Transactions of JSIDRE 64(6): 77-87 (In Japanese).

Tanaka, T. and Hirose, T. 2005. Standards and evaluation methods for seepage failure of soil in Japan -An estimation of critical hydraulic head difference for safety construction -. Memories of the Graduate School of Science and Technology, Kobe University (23-B): 41-50 (In Japanese).

Tanaka, T., Verruijt, A. and Hyashi, K. 1999. Seepage failure experiments on sand behind sheet pile. Proceedings of the International Symposium on Geotechnical Aspects of Underground Construction in Soft Ground (IS-Tokyo '99): 717-722.

Terzaghi, K. 1943. Theoretical Soil Mechanics. New York: John Wiley \& Sons: 257-261. 